\title{
Analyses of the Genomes of Chlamydial Isolates from Ruminants and Pigs Support the Adoption of the New Species Chlamydia pecorum
}

\author{
IAN E. ANDERSON, ${ }^{1}$ STUART I. F. BAXTER, ${ }^{1}$ SUSANNA DUNBAR, ${ }^{1}$ ALISTAIR G. RAE, ${ }^{\prime}$ \\ HELEN L. PHILIPS, ${ }^{2}$ MICHAEL J. CLARKSON, ${ }^{2}$ AND ALAN J. HERRING ${ }^{1 *}$ \\ Moredun Research Institute, Edinburgh EHI7 $7 \mathrm{JH},{ }^{1}$ and Department of Veterinary Clinical Science and Animal \\ Husbandry, University of Liverpool, Leahurst, Neston, South Wirral L64 $7 T E,{ }^{2}$ United Kingdom
}

\begin{abstract}
Analysis of the genomic DNAs of chlamydial isolates from sheep, cattle, and pigs was performed by Southern blot hybridization and by restriction endonuclease (RE) profiling of DNA amplified by PCR. The hybridization probes were derived from whole genomic DNA, the major outer membrane protein (MOMP) gene, the 16S rRNA gene, and an avian Chlamydia psittaci isolate plasmid. The PCR analysis used targets in the MOMP gene, the 16S rRNA gene, and the 60-kDa cysteine-rich protein gene. Together, the results showed that although there was considerable heterogeneity in the DNA sequence in the MOMP gene region, all the isolates had the same underlying total genomic RE profiles and yielded identical RE profiles for the rRNA and 60-kDa-protein gene regions. Most of the isolates were found to hybridize with the plasmid probe. Comparison of the MOMP sequence of one of the isolates (P787) with that of a known Chlamydia pecorum strain together with the results of the RE analyses allowed the conclusion that the isolates should all be classified within this new species.
\end{abstract}

The genus Chlamydia has recently been expanded, largely because of the application of measurements of genomic relatedness to discriminate further the various chlamydial species and types. Currently, there are four species recognized, Chlamydia trachomatis, $C$. psittaci, C. pneumoniae, and the newest grouping of ruminant strains proposed by Fukushi and Hirai and called $C$. pecorum $(10,12)$. Recent multistrain comparisons of the gene sequences of the major outer membrane protein (MOMP) yield phylogenetic trees which support these four species groupings $(4,22,40)$. However, DNA homology measurements $(5,9)$ indicate that the species $C$. trachomatis and $C$. psittaci could be subdivided further if it is accepted that at least $70 \%$ sequence homology is necessary for isolates to be considered as belonging to the same species (20).

An important aspect of any taxonomic system is that it should be based on criteria which can easily be applied in a standard fashion by all laboratories and which will allow accurate and rapid identification of isolates. The biological and immunological methods which have been used to identify species and subspecies types of Chlamydia are time-consuming, require considerable skill and experience, and are limited by the problems of generating and standardizing serological reagents. Recently, methods based on identifying variations in DNA sequences, usually through the use of restriction endonuclease (RE) analysis, have been applied to the problem of species and strain identification. When a chlamydial isolate has been cultured, these methods can be applied either at the whole-genome level $(9,27)$ or to subgenomic fragments by Southern blotting $(11,18,42)$. However, a substantial advance has come with the use of the PCR (33), which can be used both to detect the presence of chlamydiae in clinical samples by the amplification of specific chlamydial genes and to identify the chlamydial species and type by analysis of sequence variation in the amplified product $(6,8,17,21,44)$. The major advantage of PCR-based methods is that, unlike immunological reagents, which are finite in supply, specific primers are generally avail-

\footnotetext{
* Corresponding author. Mailing address: Moredun Research Insti-
} tute, 408 Gilmerton Rd., Edinburgh EH17 7JH, United Kingdom. able. This means that results from all laboratories can be directly compared.

Our particular interest is in chlamydial diseases of ruminants, so we wished to develop convenient methods, preferably PCR based, for the detection and rapid discrimination of strains from sheep and cattle. It has long been established that at least two types of Chlamydia infect ruminants, the immunotype 1 strains (30) associated with abortions and occasionally found in feces (37) and other strains which are associated with polyarthritis, polyserositis, encephalitis, and inapparent enteric infections (reviewed in reference 41). Studies of a subset of five strains of this latter type have found them to be genetically and antigenically distinct from all other Chlamydia spp. and to form the new species $C$. pecorum $(10,12)$. However, a variety of studies had shown that the ruminant isolates other than immunotype 1 , abortion-associated strains were biologically (2, 31 ), antigenically $(14,30)$, and genetically $(6,22,26,27) \mathrm{di}$ verse, and it was unclear if they were all members of the new species. The techniques used to establish the new species were DNA homology measurements, whole-genome RE profile comparisons, or measurements of reactions with specific sera (10). Unfortunately, none of these methods lend themselves to routine use.

This study has used DNA from a panel of 10 ruminant strains from cases of polyarthritis or enteric infection (which we designate PE strains for the purposes of this paper) together with two porcine strains and a well-characterized immunotype 1 , abortion-associated strain. The results showed that all the $\mathrm{PE}$ and porcine strains were indeed members of the newly adopted species. Moreover, two of the PCR tests yield similar but distinct products for all the strains and thus provide convenient, practical criteria for the detection and recognition of $C$. pecorum strains. In the course of the work, the complete sequence of the MOMP gene of a $C$. peconum isolate from a case of ovine arthritis was determined, and it is reported here.

\section{MATERIALS AND METHODS}

Growth of chlamydiae and preparation of DNA. Details of the chlamydia isolates used in the majority of this work are shown in Table 1 . In addition, DNA from ovine abortion strain A22 and avian isolate 725 (27) were used in individual 
TABLE 1. Isolates of $C$. psittaci

\begin{tabular}{lllll}
\hline \multicolumn{1}{c}{ Isolate } & Host & $\begin{array}{c}\text { Clinical condition } \\
\text { associated with } \\
\text { isolation }\end{array}$ & Source & \\
& & Reference(s) \\
\hline B577 & Sheep & Abortion & 1 & 30 \\
LW613 & Cow & Polyarthritis & 1 & 30 \\
66P130 & Cow & Normal (feces) & 1 & 30 \\
L71 & Pig & Polyarthritis & 1 & 30 \\
1710S & Pig & Abortion & 1 & 30 \\
JP1751 & Sheep & Normal (feces) & 1 & 30 \\
R69 (NI E1) & Sheep & Normal (feces) & 2 & 26 \\
W73 (NI E2) & Sheep & Normal (feces) & 2 & 26 \\
84/604 & Sheep & Normal (feces) & 3 & 2 \\
P787 & Sheep & Polyarthritis & 3 & 2,27 \\
T13/1 & Sheep & Normal (feces) & 4 & \\
T13/5 & Sheep & Normal (feces) & 4 & \\
T7/2 & Sheep & Normal (feces) & 4 & \\
\hline
\end{tabular}

${ }^{a}$ Sources of isolates were as follows: 1, J. Storz; 2, B. Markey, Dublin, Ireland; 3, Moredun Research Institute (isolated there); and 4, Department of Veterinary Clinical Science, University of Liverpool (isolated there).

experiments. Most of the isolates were grown in developing chicken embryos, and DNA was prepared from a homogenized suspension of infected yolk sacs by extraction with phenol following digestion with proteinase $\mathrm{K}(35)$. The DNAs from isolates P787, A22, and 725 were extracted from purified elementary bodies as described previously (27). Genomic DNA or amplified gene fragments were cleaved with the specified REs, as detailed by the manufacturer (Boehringer Mannheim, Lewes, United Kingdom), in 50- $\mu$ l reaction volumes.

Agarose gel electrophoresis and Southern blotting. DNA fragments were separated by electrophoresis in a $0.8 \%$ agarose gel containing $0.4 \mu \mathrm{g}$ of ethidium bromide per $\mathrm{ml}$ using a voltage gradient of $1 \mathrm{~V} / \mathrm{cm}$ for $16 \mathrm{~h}$ and visualized with UV light. Approximately $2 \mu \mathrm{g}$ of DNA was loaded into each lane. Gel loadings were estimated by comparison of the UV fluorescence produced by small samples of unrestricted DNA. The molecular size standards were the 1-kb ladder (Bethesda Research Laboratories Ltd., Paisley, Scotland). DNA was transferred to nitrocellulose membranes (BA85; Schleicher \& Schuell) by the method of Smith and Summers (38).

Probe preparation and hybridization. The $16 \mathrm{~S}$ rRNA probe was synthesized from a 1,300-bp MboI fragment of the 16 S gene (45) from abortion strain \$26/3 cloned into $\mathrm{pBS}^{+}$(Stratagene, Cambridge, United Kingdom) at the BamHI site. The probe was prepared by transcription of the DNA digested with EcoRV by using T3 bacteriophage DNA-dependent RNA polymerase. Conditions were those specified by the polymerase supplier (Pharmacia, St. Albans, United Kingdom) except that the reaction mixture contained $6.5 \mathrm{mM}$ UTP and $3.5 \mathrm{mM}$ digoxigenin (Dig) (Boehringer Mannheim). The reaction yields a single-stranded RNA probe, $1 \mathrm{~kb}$ in length, of opposite polarity to the 16S rRNA (3).

The P787 MOMP probe was prepared by amplifying the MOMP gene from genomic DNA by PCR (see below), yielding a 1,176-bp fragment containing the whole MOMP coding region. The fragment had a single, highly conserved HindIII site at base 1057. The amplified product was phosphorylated (35) and cloned, after cleavage with HindIII, into SmaI-HindIII-digested $\mathrm{pBS}^{+}$. The cloned fragment of about $1 \mathrm{~kb}$ from the $5^{\prime}$ end of the gene was excised from the plasmid by digestion with HindIII and KpnI. The chlamydial plasmid probe was a 5.9-kb cloned Hindlil fragment derived from avian isolate 725 (28). Both of these probes were purified by recovery of the appropriate restriction fragments from agarose gels by adsorption onto powdered glass (43) using Geneclean (Bio 101, Inc., Vista, Calif.) prior to labelling. The DNA probes were labelled with Dig-dUTP by random priming with hexanucleotides (7) using the conditions specified in the Dig labelling kit (Boehringer Mannheim).

Hybridization of Southern blots was performed by standard techniques (35) using the blocking agent supplied in the Dig labelling kit. The hybridization buffer consisted of $0.75 \mathrm{M} \mathrm{NaCl}-75 \mathrm{mM} \mathrm{Na}$-citrate $(\mathrm{pH} \mathrm{7.0)}(5 \times \mathrm{SSC})$ containing $0.1 \%$ (wt/vol) sodium dodecyl sulfate (SDS), $5 \%$ blocking agent, and $50 \%$ (vol/ vol) formamide. The hybridization was performed overnight at $42^{\circ} \mathrm{C}$, and the blots were washed twice in $2 \times$ SSC- $0.1 \%$ SDS for $5 \mathrm{~min}$ at room temperature and twice in $0.1 \times \mathrm{SSC}-0.1 \% \mathrm{SDS}$ at $42^{\circ} \mathrm{C}$ for $15 \mathrm{~min}$. Hybridized probe was detected by using alkaline phosphatase-conjugated anti-Dig antibody and the color reagents provided in the Dig labelling kit (Boehringer Mannheim).

For Fig. 1, in which the signal strength was highly variable, the blot image was captured by using a model GS-670 imaging densitometer (Bio-Rad, Hertfordshire, United Kingdom), and the associated Molecular Analyst software was used to increase the contrast in the weak signal lanes ( 1 to 6$)$ and to reduce the contrast level in the overdeveloped lane (lane 10). No transformations of the raw data were made.

PCR. The PCR mixtures consisted of 1 to $10 \mathrm{ng}$ of heat-denatured chlamydial DNA in a final volume of $25 \mu \mathrm{l}$ containing $10 \mathrm{mM}$ Tris (pH 8.3 ), $3 \mathrm{mM} \mathrm{MgCl}$,
$50 \mathrm{mM} \mathrm{KCl}, 10 \mu \mathrm{l}$ of gelatin per $\mathrm{ml}, 0.045 \%$ Nonidet $\mathrm{P}-40,0.045 \%$ Tween 20 , and $0.25 \mathrm{U}$ of Taq DNA polymerase (Cetus Corp., Emeryville, Calif.). Each mixture was overlaid with $50 \mu \mathrm{l}$ of light mineral oil, and 25 cycles of amplification were performed. Cycle conditions and primers for MOMP and the $60-\mathrm{kDa}$ protein gene were as described by Denamur et al. (6) and Watson et al. (44), respectively. For the amplification of the 16S rRNA gene (15), the primers had the sequences GTTGAGGGAGAGTCTATGGGATATCA and TACGACACGGATAGG GTTGAGACTATCCAC. Cycle conditions were denaturation for $60 \mathrm{~s}$ at $94^{\circ} \mathrm{C}$ primer annealing for $90 \mathrm{~s}$ at $36^{\circ} \mathrm{C}$, and polymerization for $100 \mathrm{~s}$ at $72^{\circ} \mathrm{C}$. The polymerization time was extended by $3 \mathrm{~s}$ each cycle. A $5-\mu \mathrm{l}$ aliquot of the reaction mixture was digested with the appropriate RE and analyzed by polyacrylamide gel electrophoresis (PAGE).

For the cloning of the P787 MOMP gene, the coding region was amplified by using primers with the sequences GAGTATGAATTCACTCTTGAAATCGGC and TCCTTAGAATCTGAATTGAGC under conditions identical to those used for the 16S rRNA gene amplification.

PAGE. Amplified DNA fragments were digested with REs, phenol extracted (35), and analyzed by PAGE followed by silver staining essentially as described by Herring et al. (16), with the exception that the gels used were $10 \%$ acrylamide and were not bonded to the plates with silane. The small fragments in the $1-\mathrm{kb}$ ladder were used as size standards.

Sequence analysis of the P787 MOMP gene. Sequence analysis was performed by the dideoxy method of Sanger et al. (36), using a T7 sequencing kit (Pharmacia LKB Biotechnology). The initial template was $\mathrm{pBS}^{+}$plasmid containing the cloned $5^{\prime}$ end of the P787 MOMP gene described above. Once preliminary sequence data were obtained and useful RE sites were identified, parts of the gene were subcloned into M13 bacteriophage vectors mp18 and mp19 and sequenced by using a single-stranded DNA template. The sequence was com pleted by cloning (using a strategy similar to that described above) and sequencing the $3^{\prime} 119$-bp fragment from the HindIII restriction site to the end of the gene.

Nucleotide sequence accession number. The PCR product from isolate P787 was cloned and sequenced, and the sequence has been deposited in the GenBank database under accession no. Z18756.

\section{RESULTS}

The results obtained when labelled whole P787 genome was used to probe blots of EcoRI-digested DNAs of the 13 isolates are shown in Fig. 1. The PE and porcine isolates all showed similar profiles of reacting bands, but no hybridization was observed with the ovine abortion immunotype 1 isolate B577. The amount of hybridization signal varied between isolates despite the fact that the gel loadings were approximately equal in terms of DNA. This was probably due to differences in the levels of chlamydiae in the various yolk sac harvests. The P787 DNA in Fig. 1, lane 10, which was homologous to the probe and the only sample derived from purified elementary bodies, gave a very strong hybridization signal which obscures the profile in Fig. 1 but was clearly seen to have the common banding pattern during blot development. This pattern can also be seen in lane $10 \mathrm{a}$, in which the contrast has been reduced by using a gel image analysis program.

When similar blots of DNA digested with EcoRI were hybridized with a probe derived from the ovine abortion strain 16S rRNA gene, all isolates produced a strongly reactive band at $2.0 \mathrm{~kb}$ (Fig. 2). However, the PE and porcine isolates also gave a band at $0.76 \mathrm{~kb}$, while strain $\mathrm{B} 577$ gave a large-molecular-size band, which was outside the range of our standards, at approximately $20 \mathrm{~kb}$. This latter banding pattern had also been previously observed for a further six abortion isolates from the United Kingdom (3). The samples in lanes 11 through 13 were only partially digested.

Southern blotting analysis was also performed with a plasmid probe derived from an avian isolate of $C$. psittaci (26). The enzyme used to digest the samples was HindIII, and the results are shown in Fig. 3. Parental avian isolate 725 (28) was used as a positive control in place of the ovine abortion strain, which lacks a plasmid. Positive hybridization was seen for 8 of the 11 isolates, with a band of $1.0 \mathrm{~kb}$ for 7 isolates and $1.2 \mathrm{~kb}$ for isolate $66 \mathrm{P} 130$. The positive control gave a strong signal at 6 $\mathrm{kb}$, as expected (28).

Hybridization of Bam $\mathrm{HI}$ digests with a probe prepared from 


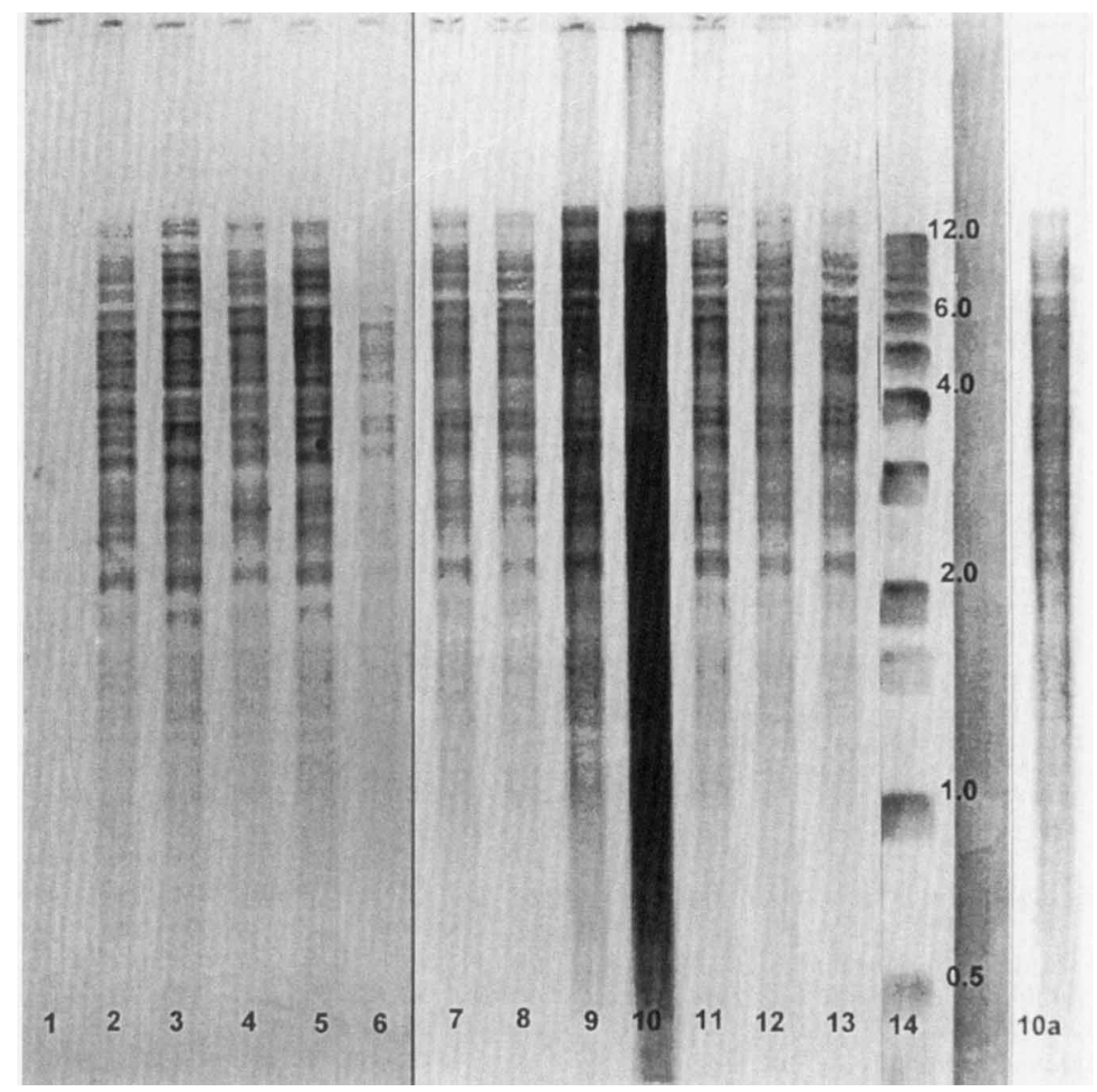

FIG. 1. Southern blot analysis of the panel of chlamydial genomic DNAs after cleavage with EcoRI using a probe prepared from P787 genomic DNA. Lane 1, B577; lane 2, LW613; lane 3, 66P130; lane 4, L71; lane 5, 1710S; lane 6, JP1751; lane 7, R69; lane 8, W73; lane 9, 84/604; lane 10, P787; lane 11, T13/1; lane 12, T13/5; lane 13 , T7/2; lane 14, size markers (1-kb ladder). Lane 10a is the same as lane 10, but the grey levels have been adjusted to show the underlying pattern of bands.

the P787 MOMP gene coding region gave a single hybridizing band in each of the PE and porcine isolates but of three DNA fragment sizes. Isolates 66P130, R69, W73, and 84/604 gave bands of $8.1 \mathrm{~kb}$; isolates $1710 \mathrm{~S}, \mathrm{~T} 13 / 1$, and T13/5 gave bands of $5.9 \mathrm{~kb}$; and isolates LW613, L71, JP1751, P787, and T7/2 gave bands of $4.0 \mathrm{~kb}$. No hybridization was detected with the B577 DNA.

Analysis of the panel by PCR amplification was performed initially on a fragment of approximately $1 \mathrm{~kb}$ from the coding region of the MOMP gene. Amplified DNA was digested with AluI and analyzed by PAGE, and the results are shown in Fig. 4. B577 gave the pattern predicted for an ovine abortion strain $(17,18)$, but the $12 \mathrm{PE}$ and porcine isolates yielded nine distinct profiles. Isolates LW613 (Fig. 4, lane 2) and JP1751 (lane 6) show identical profiles, as do the Irish isolates R69 (lane 7) and W73 (lane 8). Fecal isolate T13/5 (Fig. 4, lane 12) gave a profile which clearly contained all the bands of the abortion isolate, but other bands similar to those seen for T13/5 were also present. This result, which was consistently observed with amplifications from several extractions of the yolk sac stock, suggests that this isolate has become cross-contaminated with the abortion strain at some stage. Inspection of the individual profiles shows that, although different, some clearly have several bands in common. For example, 1710S (Fig. 4, lane 5) and $84 / 604$ (lane 9) are clearly related, since the profiles differ by only a single major band.

In order to substantiate that correct amplification of the MOMP gene was occurring, the PCR product from isolate
P787 was cloned and sequenced. The resulting DNA sequence was typical of a MOMP gene. The sequence contained the "arthritis group"-specific sequence used by Kaltenboeck et al. (21) to detect this type of chlamydia in a multiplex PCR. The peptide sequence deduced from the P787 MOMP DNA sequence is shown in Fig. 5, aligned with the partial sequences of four other arthritis group isolates which have been subsequently reclassified as $C$. pecorum (22). There is clearly a high degree of homology between P787 and these isolates, with substitutions largely confined to the four variable segments (39), with most variation in variable segment 1 . Numbers 1 to 10 above the sequence indicate positions in the conserved segments of the MOMP gene which, in a multiple sequence alignment of MOMP sequences from all four chlamydial species (22), vary to the extent that three separate amino acids are found. There is only one substitution in one isolate observed in all 10 variable positions, a finding which confirms the close relationship between the isolates.

Since the MOMP gene AluI profiles showed such a high degree of variation, two other loci were investigated. The first of these was the 16S rRNA gene, which was amplified with a primer pair chosen from regions in the $C$. psittaci gene which were clearly different from the $E$. coli sequence (45). These primers amplify a 640-bp fragment which was analyzed by digestion with MaeI; the resulting profiles are shown in Fig. 6. All isolates yield a profile of five fragments which is consistent with the published sequence of the $C$. psittaci $16 \mathrm{~S}$ rRNA sequence. However, for all the $\mathrm{PE}$ and porcine isolates, the 


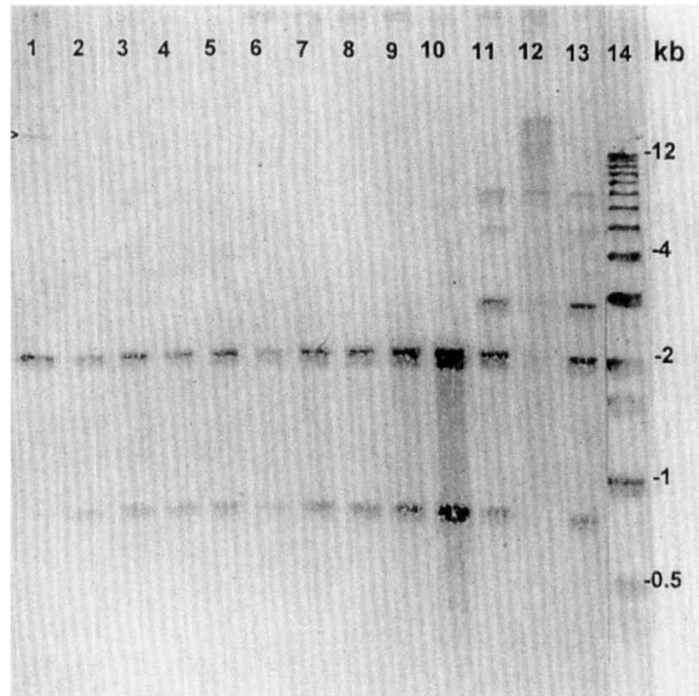

FIG. 2. Southern blot analysis of the panel of chlamydial genomic DNAs after cleavage with $E$ coRI using a probe prepared from the $C$. psittaci $16 \mathrm{~S}$ rRNA gene. Sample DNAs were loaded in the same lanes as in Fig. 1. A faint band at about $20 \mathrm{~kb}$ (arrowhead, lane 1) is indicated.

largest MaeI fragment was slightly larger than that of the ovine abortion isolate.

The final PCR analysis used the primers described by Watson et al. (44) which amplify the variable $5^{\prime}$ region at the end of the gene encoding the $60-\mathrm{kDa}$ cystein-rich protein (CrP). These primers yielded a fragment of about $570 \mathrm{bp}$ with all isolates tested. When this fragment was digested with the enzyme $A l u \mathrm{I}$, the profiles shown in Fig. 7 were obtained; ovine abortion isolate B577 yielded fragments of 335 and $235 \mathrm{bp}$, while all the $\mathrm{PE}$ and porcine isolates gave fragments of 390 and $180 \mathrm{bp}$. The Scottish ovine abortion type strain, A22, gave fragments identical to those of B577 (data not shown).

\section{DISCUSSION}

Taken together, the results show that all the PE isolates and the two porcine isolates have similar genomes when analyzed outside the MOMP gene and are members of the new species C. pecorum. This association is possible because one of the

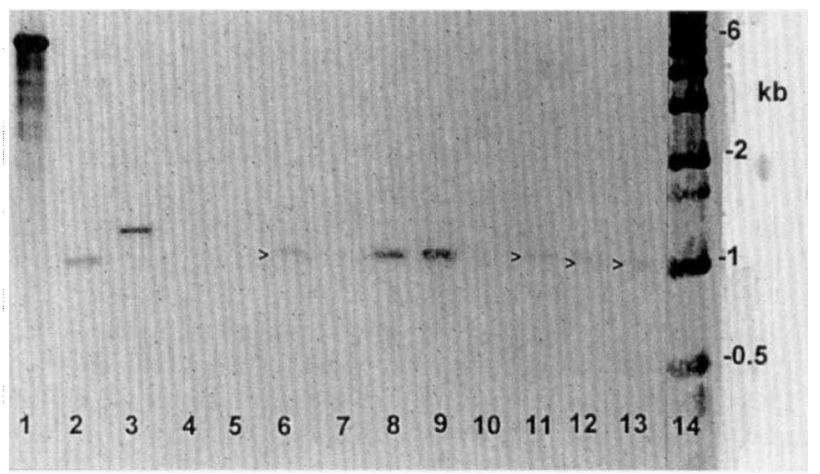

FIG. 3. Southern blot analysis of the panel of chlamydial genomic DNAs after cleavage with HindIII using a probe prepared from a plasmid derived from an avian isolate of $C$. psittaci. Sample DNAs were loaded in the same lanes as in Fig. 1, with the exception that lane 1 contained the avian isolate 725 genomic DNA in place of the ovine abortion strain B577 sample. Faint bonds in lanes 6 , 11,12 , and 13 (arrowheads) are indicated.

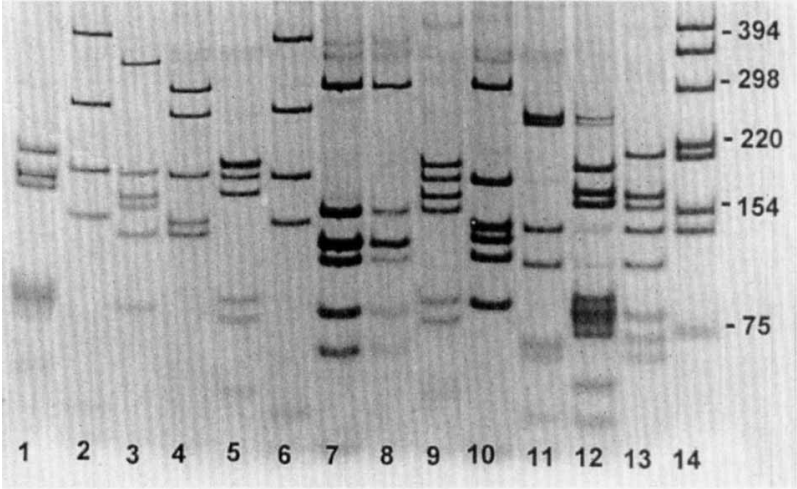

FIG. 4. PAGE analysis of PCR-amplified MOMP genes digested with $A l u \mathbf{I}$. Sample DNAs were loaded in the same lanes as in Fig. 1. Fragment sizes (in base pairs) are indicated on the right.

isolates used, LW613, from a case of bovine polyarthritis, has been found to have a MOMP sequence identical to that of Bo/E58, the type strain for the $C$. peconum species (22). Because of cross representation of strains in our panel with those used by others, it is also possible to extend this identification, as explained below.

Strong evidence for the identification of the isolates as $C$. pecorum comes from the results obtained by Southern blotting with the total-genome probe. This method, which was first used by Fukushi and Hirai (9), combines the advantages of direct agarose gel analysis and DNA homology assay but avoids the need to prepare highly purified DNA from each strain, which we, in common with Kuroda-Kitagawa et al. (24), have found difficult for these strains. All the isolates gave the same underlying pattern of bands, confirming that they are all members of the same species. No homology between the C. pecorum probe and the abortion isolate was found.

Total-genome RE analysis of chlamydial DNA has been performed in two further ways. Analysis of RE digests using agarose gels and ethidium bromide staining allows fragments in the range of 25 to $1 \mathrm{~kb}$ to be resolved, but the complexity of the chlamydial genome means that individual fragments are not well separated from one another over most of this size range. Nevertheless, the profiles produced by different chlamydial species and types can be readily differentiated, as shown originally by Fukushi and Hirai (9), and $C$. pecorum strains have similar profiles (10). Rodolakis and Souriau (32) used this technique to compare a panel of strains containing six strains which were noninvasive in a mouse infection test (31) and which included strain LW679, which can be identified as $C$. pecorum since it is immunologically related to LW613 (30). All of their noninvasive strains, except for strain iB1, had the same profile as LW613, showing that they too are C. pecorum strains. Andersen and Tappe (1) also showed that type strain Bo/E58 had a profile similar to that of an ovine polyarthritis isolate.

Polyacrylamide gel analysis with band detection by silver staining allows the comparison of a subset of individual RE fragments in the approximate size range of 5 to $0.5 \mathrm{~kb}(27,29)$ and is a good method for fine comparison of strains. Markey et al. (26) have used this technique to compare a panel of 10 non-immunotype 1 strains which included P787. Their results show that, although there are numerous differences in individual fragments, the overall distributions of fragments are similar and hence they all appear to be $C$. pecorum strains. The considerable number of minor differences between the isolates contrasted with the striking homogeneity found in the abortion strains $(26,27)$. 


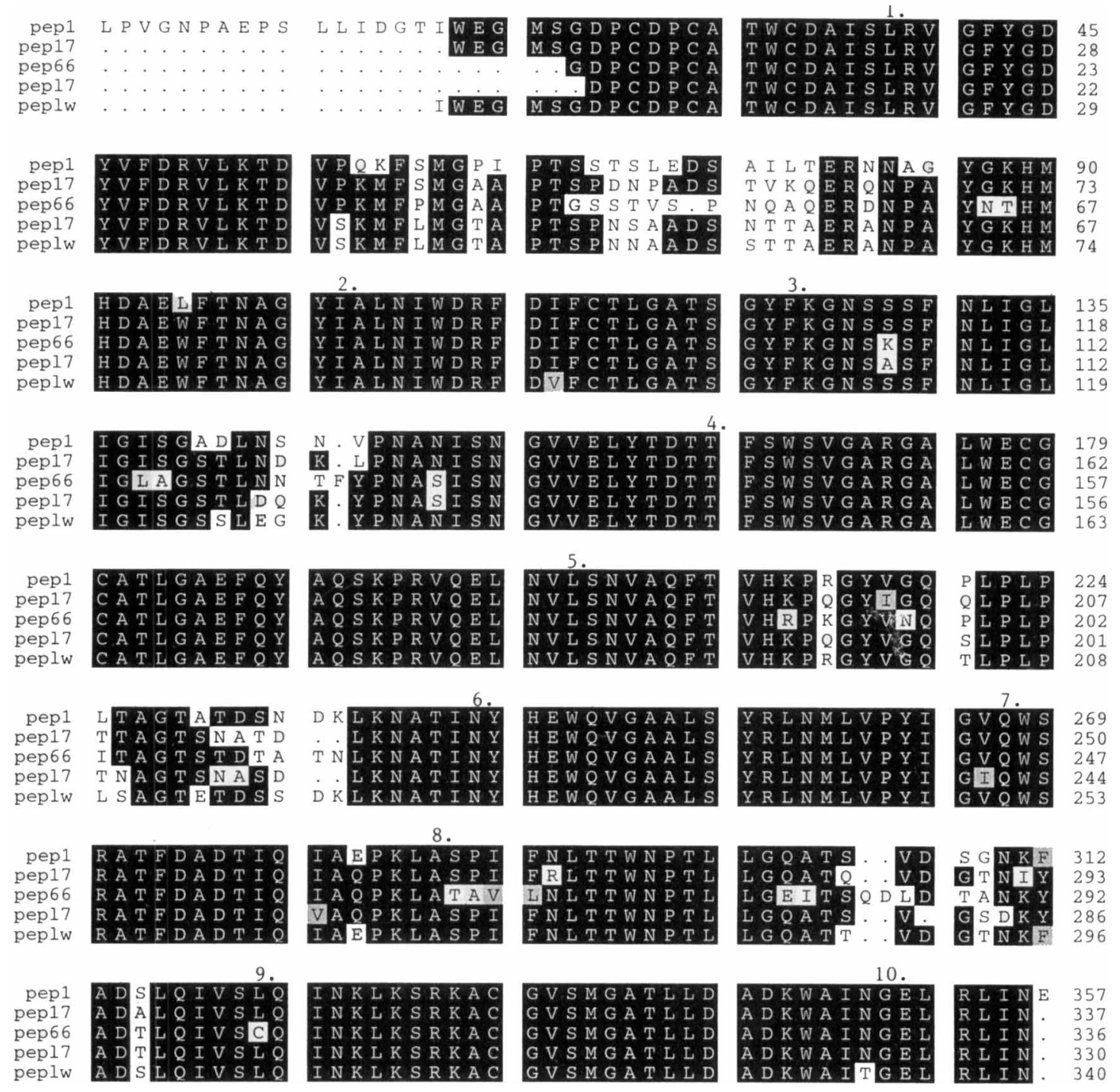

FIG. 5. Multiple alignment of the derived MOMP sequences from isolate P787 (pep1), 1710S (pep17), 66P130 (pep66), L71 (pep17), and LW613 (pep1w). Complete conservation (black areas), no relationship (white areas), and substitutions with amino acids of similar properties (shaded areas) are indicated. Numbers 1 to 10 indicate variable positions in the conserved segments (see text).

Variation in the RE profiles of individual genes and their flanking regions has been studied by Southern blotting, a method first used for this purpose by Timms et al. (42). The results obtained with the $16 \mathrm{~S}$ rRNA probe are consistent for all the $C$. pecorum isolates. They agree with those recently published by Fukushi and Hirai (11), who used a range of probes from the rRNA coding region of the $C$. psittaci genome. (Our probe spans the left end of their probe P3 and the right end of their probe $\mathrm{P} 4$.) The above results confirm the identification of a 2.0-kb EcoRI fragment common to C. psittaci and C. pecorum. However, the $0.76-\mathrm{kb}$ band in the $C$. peconum isolates was not found by Fukushi and Hirai because it was outside the size range of fragments which remained on their gels. The profile for the abortion strains is also in agreement with their results (3).
Hybridization with the plasmid probe showed that most, but not all, of the $C$. peconum isolates contain avian $C$. psittaci plasmid-related sequences which, judging from the size of the cross-hybridizing fragments, were clearly different from those of the avian isolate. The probe has been shown to detect homologous sequences in C. trachomatis (28) and thus contains the common sequence described by Lusher et al. (25) and Hugall et al. (19) which is found in both $C$. psittaci and $C$. trachomatis plasmids and is thought to be the origin of replication. Hugall et al. (19) characterized a plasmid from a sporadic bovine encephalomyelitis isolate, which may well be a $C$. pecorum strain, and found it to be identical to a plasmid from a koala isolate. It would be interesting to determine if this class of plasmid is widely distributed in $C$. pecorum strains. The presence of plasmids in the nonhybridizing strains cannot be 


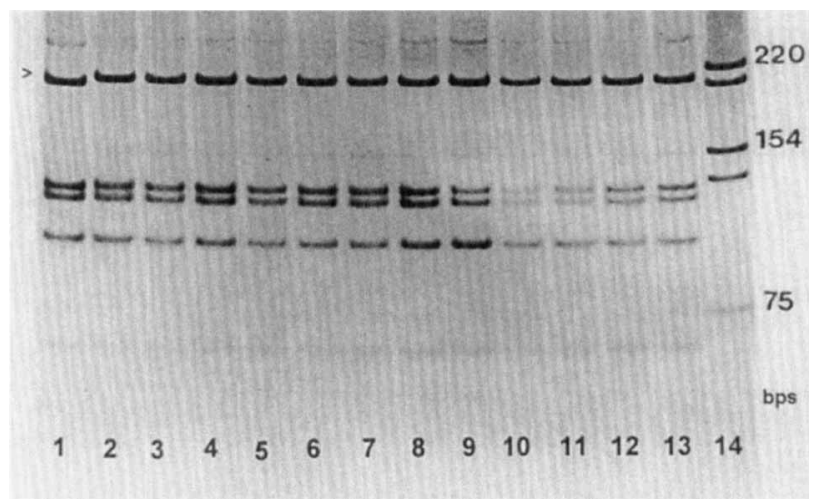

FIG. 6. PAGE analysis of PCR-amplified 16S rRNA genes digested with MaeI. Sample DNAs were loaded in the same lanes as in Fig. 1. The band with different mobility in the PE and pig isolates (arrowhead) is indicated.

ruled out, but, if present, they are of a novel type which lacks the common sequence.

The results with the P787 MOMP probe divided our $C$. pecorum isolates into three groups, a result consistent with the polymorphic nature of the MOMP gene coding region found by PCR-AluI profiling and by sequence analysis (22).

The results of the PCR-AluI analysis of the MOMP gene are also consistent with the heterogeneity of sequences of $C$. pecorum MOMP genes found by Kaltenboeck et al., who studied the phylogenetic relationships within the whole genus by MOMP gene comparison (22), and by Denamur et al. (6), who also used the PCR-AluI profiling method. The panel of ruminant isolates used by Denamur et al. included 12 which were noninvasive in the mouse infection assay (31), five of which can identified as $C$. pecorum from the RE profile analysis of Rodolakis and Souriau (32) (see above). These five isolates displayed four separate $A l u$ I MOMP profiles. Isolates R69 and W73, which are shared with our panel, displayed a further distinct profile (which we confirm), and the remaining five noninvasive isolates, which included the unidentified strain iBl, showed a further three profiles.

The variation in the MOMP gene is also consistent with the immunological data. Fukushi and Hirai (10) report that their original panel of $C$. pecorum isolates contained three serovars, as judged by immunoblot analysis of the MOMP. Griffiths et al. (14) found that the MOMPs of only two of four ovine intestinal PE strains cross-reacted with an ovine postabortion serum by

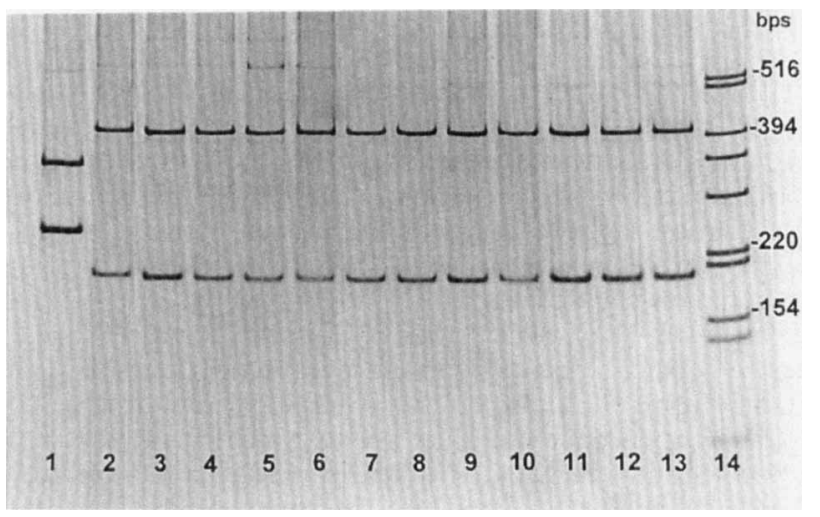

FIG. 7. PAGE analysis of PCR-amplified genes encoding 60-kDa $\mathrm{CrP}$ digested with AluI. Sample DNAs were loaded in the same lanes as in Fig. 1. immunoblotting. Kuroda-Kitagawa et al. (24) derived four anti-C. pecorum MOMP monoclonal antibodies, but none proved specific for $C$. pecorum, nor did a further nine monoclonal antibodies which recognized proteins in the size range of 56 to $64 \mathrm{kDa}$.

Other immunological tests, less well-defined in terms of the target antigen, also show variation. Perez-Martinez and Storz reported that their isolates, which were included in our panel, represented five immunotypes as determined by a microimmunofluorescence assay (30). However, isolates LW613 and JP1751 have been found to have identical MOMP sequences (22), but they belong to different immunotypes. Thus, the antigens which determine immunotype may not be the MOMP for the $C$. pecorum strains. Markey et al. (26) found that four monoclonal antibodies raised against isolate $\mathrm{R} 69$ reacted only with the homologous strain or a subset of 4 of their $10 C$. pecorum isolates, and recently Salinas et al. (34) reported eight patterns of response to monoclonal antibodies raised against strain $\mathrm{iBl}$ among 14 other noninvasive strains, with no single antibody reacting with all strains.

In contrast to the results with the MOMP gene, the PCR and RE analyses of the 16S rRNA gene and the gene encoding the $60-\mathrm{kDa}$ CrP yielded consistent results for the entire panel of $C$. pecorum isolates and gave profiles which were different from that of the C. psittaci isolate. The MaeI profiling of the $16 \mathrm{~S}$ rRNA gene fragment has thus been found to give different patterns for each of the four currently recognized species (15). The $C$. trachomatis gene sequence has an extra MaeI site (46), while the $C$. pneumoniae sequence lacks a site (13). Unfortunately, the distinctive feature of the $C$. pecorum profile, the slightly lower mobility of the largest RE fragment, requires careful gel analysis to be detected, and it may be that sequence analysis of the $C$. pecorum $16 \mathrm{~S}$ rRNA gene will reveal a better means of discriminating this sequence from the other chlamydial genes. However, the AluI analysis of the $60-\mathrm{kDa}$-protein gene gives fragments which are easily differentiated from those of the abortion strain. The fragments are also distinct from those which would be produced by $A l u \mathrm{I}$ digestion of the relevant part of the $60-\mathrm{kDa}$-protein genes of avian $C$. psittaci, $C$. pneumoniae, or $C$. trachomatis as deduced by computer-assisted mapping of the relevant sequences (44). The use of the $60-\mathrm{kDa}$ PCR, which has been shown to detect all four chlamydial species but to give no product with a wide range of other bacteria (44), combined with RE analysis of the product thus seems to be the simplest strategy available at the moment for the initial recognition of $C$. pecorum isolates.

These findings support the adoption of the new species and should make isolate recognition in ruminants and pigs, which are also infected by $C$. trachomatis strains (23), an easier task. It is clear that there is considerable genetic variation within the C. pecorum species, and the question which must now be addressed is whether the various types, identified immunologically and by the sequence variation in their MOMP genes, can be correlated with biological variation in the spectrum of disease with which they are associated in the same fashion as the human serovars of $C$. trachomatis.

\section{ACKNOWLEDGMENTS}

We thank Johannes Storz of Lousiana State University and Brian Markey of University College, Dublin, Ireland, for providing chlamydial isolates.

This work was funded by the Scottish Office Agriculture and Fisheries Department and by a grant to M.J.C. and H.L.P. from the Agriculture and Food Research Council. 


\section{REFERENCES}

1. Andersen, A. A., and J. P. Tappe. 1989. Genetic, immunologic and pathologic characterisation of avian chlamydial strains. J. Am. Vet. Med. Assoc. 195: $1512-1516$

2. Anderson, I. E., and T. A. Baxter. 1986. Chlamydia psittaci: inclusion morphology in cell culture and virulence in mice of ovine isolates. Vet. Rec. 119:453-454.

3. Baxter, S. I. F. 1990. Development of molecular techniques for the detection of Chlamydia psittaci infection in sheep and the typing of chlamydial isolates. Ph.D. thesis. University of Edinburgh, Edinburgh.

4. Carter, M. W., A. H. Al-Mahdawi, I. G. Giles, J. D. Treharne, M. E. Ward, and I. N. Clarke. 1991. Nucleotide sequence and taxonomic value of the major outer membrane protein gene of Chlamydia pneumoniae IOL-207. J. Gen. Microbiol. 137:465-475.

5. Cox, R. L., C.-C. Kuo, J. T. Grayston, and L. A. Campbell. 1988. Deoxyribonucleic acid relatedness of Chlamydia sp. isolate TWAR to Chlamydia trachomatis and Chlamydia psittaci. Int. J. Syst. Bacteriol. 38: 265-268.

6. Denamur, E., C. Sayada, A. Souriau, J. Orfila, A. Rodolakis, and J. Elion. 1991. Restriction pattern of the major outer membrane protein gene provides evidence for a homogeneous invasive group among ruminant isolates of Chlamydia psittaci. J. Gen. Microbiol. 137:2525-2530.

7. Feinberg, A. P., and B. Vogelstein. 1983. A technique for radiolabeling to high specific activity. Anal. Biochem. 132:6-13.

8. Frost, E. H., S. Deslandes, and D. Bourgaux-Ramoisy. 1990. Typing Chlamydia isolates with the polymerase chain reaction, p. 499-502. In W. R. Bowie et al. (ed.), Chlamydial infections. Cambridge University Press, Cambridge.

9. Fukushi, H., and K. Hirai. 1989. Genetic diversity of avian and mammalian Chlamydia psittaci isolates and relation to host origin. J. Bacteriol. 171:28502855.

10. Fukushi, H., and K. Hirai. 1992. Proposal of Chlamydia pecorum sp. nov. for Chlamydia isolates derived from ruminants. Int. J. Syst. Bacteriol. 42:306308.

11. Fukushi, H., and K. Hirai. 1993. Restriction fragment length polymorphisms of rRNA as genetic markers to differentiate Chlamydia spp. Int. J. Syst. Bacteriol. 43:613-617.

12. Fukushi, H., and K. Hirai. 1993. Chlamydia pecorum-the fourth species of the genus Chlamydia. Microbiol. Immunol. 37:515-522.

13. Gaydos, C. A., L. Palmer, T. C. Quinn, S. Falkow, G. F. Brooks, and J. J. Eiden. 1993. Phylogenetic relationship of Chlamydia pneumoniae to Chlamydia psittaci and Chlamydia trachomatis as determined by analysis of $16 \mathrm{~S}$ ribosomal DNA sequences. Int. J. Syst. Bacteriol. 43:610-612.

14. Griffiths, P. C., H. L. Philips, M. Dawson, and M. J. Clarkson. 1992. Antigenic and morphological differentiation of placental and intestinal isolates of Chlamydia psittaci of ovine origin. Vet. Microbiol. 30:165-177.

15. Herring, A. J. 1993. Typing Chlamydia psittaci-a review of methods and recent findings. Br. Vet. J. 159:455-475.

16. Herring, A. J., N. F. Inglis, C. K. Ojeh, D. R. Snodgrass, and J. D. Menzies. 1982. Rapid diagnosis of rotavirus infection by direct detection of viral nucleic acid in silver-stained polyacrylamide gels. J. Clin. Microbiol. 16:473477.

17. Herring, A. J., T. W. Tan, and S. Baxter. 1990. Chlamydial abortion in sheep: molecular approaches to vaccination, pathogen detection and isolate typing, p. 378-382. In W. R. Bowie et al. (ed.), Chlamydial infections. Cambridge University Press, Cambridge.

18. Herring, A. J., T. W. Tan, S. Baxter, N. F. Inglis, and S. Dunbar. 1989. Sequence analysis of the major outer membrane protein gene of an ovine abortion isolate of Chlamydia psittaci. FEMS Microbiol. Lett. 65:153-158.

19. Hugall, A., P. Timms, A. A. Girges, and M. F. Lavin. 1989. Conserved sequences in chlamydial plasmids. Plasmid 22:91-98.

20. Johnston, J. L. 1984 . Nucleic acids in bacterial classification, p. 8-11. In N. R. Krieg and J. G. Holt (ed.), Bergey's manual of systematic bacteriology, vol. 1. Williams \& Wilkins, Baltimore.

21. Kaltenboeck, B., K. Kousoulas, and J. Storz. 1992. Two-step polymerase chain reactions and restriction endonuclease analyses detect and differentiate ompA DNA of Chlamydia spp. J. Clin. Microbiol. 30:1098-1104.

22. Kaltenboeck, B., K. G. Kousoulas, and J. Storz. 1993. Structures of and allelic diversity and relationships among the major outer membrane protein (ompA) genes of the four chlamydial species. J. Bacteriol. 175:487-501.

23. Kaltenboeck, B., and J. Storz. 1992. Biological properties and genetic analysis of the ompA locus in chlamydiae isolated from swine. Am. J. Vet. Res. 53:1582-1587.
24. Kuroda-Kitagawa, Y., C. Suzuki-Muramatsu, T. Yamaguchi, H. Fukushi, and K. Hirai. 1993. Antigenic analysis of Chlamydia pecorum and mammalian Chlamydia psittaci by use of monoclonal antibodies to the major outer membrane protein and to 56 to $64 \mathrm{kD}$ protein. Am. J. Vet. Res. 54:709-712.

25. Lusher, M., C. C. Storey, and S. J. Richmond. 1989. Plasmid diversity within the genus Chlamydia. J. Gen. Microbiol. 135:1145-1151.

26. Markey, B. K., M. S. McNulty, D. Todd, and D. P. Mackie. 1993. Comparison of ovine abortion and non-abortion isolates of Chlamydia psittaci using inclusion morphology, polyacrylamide gel electrophoresis, restriction endonuclease analysis and reactivity with monoclonal antibodies. Vet. Microbiol. 35:151-159.

27. McClenaghan, M., A. J. Herring, and I. D. Aitken. 1984. Comparison of Chlamydia psittaci isolates by DNA restriction endonuclease analysis. Infect. Immun. 45:384-389.

28. McClenaghan, M., J. R. Honeycombe, B. J. Bevan, and A. J. Herring. 1988. Distribution of plasmid sequences in avian and mammalian isolates of Chlamydia psittaci. J. Gen. Microbiol. 134:559-565.

29. McClenaghan, M., N. F. Inglis, and A. J. Herring. 1991. Comparison of isolates of Chlamydia psittaci of ovine, avian and feline origin by analysis of polypeptide profiles from purified elementary bodies. Vet. Microbiol. 26: 269-278.

30. Perez-Martinez, J. A., and J. Storz. 1985. Antigenic diversity of Chlamydia psittaci of mammalian origin determined by microimmunofluorescence. Infect. Immun. 50:905-910.

31. Rodolakis, A., F. Bernard, and F. Lantier. 1989. Mouse models for evaluation of virulence of Chlamydia psittaci isolated from ruminants. Res. Vet. Sci. 46:34-39.

32. Rodolakis, A., and A. Souriau. 1992. Restriction endonuclease analysis of DNA from ruminant Chlamydia psittaci and its relation to mouse virulence. Vet. Microbiol. 31:263-271.

33. Saiki, R. K., D. H. Gelfand, S. Stoffel, S. J. Scharf, R. Higuchi, G. T. Horne, K. B. Mullis, and H. A. Erlich. 1988. Primer directed enzymatic amplification of DNA with a thermostable DNA polymerase. Science 239:487-491.

34. Salinas, J., A. Souriau, F. Cuello, and A. Rodolakis. 1995. Antigenic diversity of ruminant Chlamydia psittaci strains demonstrated by the indirect microimmunofluorescence test with monoclonal antibodies. Vet. Microbiol. 43; 219-226.

35. Sambrook, J., E. F. Fritsch, and T. Maniatis. 1989. Molecular cloning: a laboratory manual, 2nd ed. Cold Spring Harbor Laboratory Press, Cold Spring Harbor, N.Y.

36. Sanger, F., S. Nicklen, and A. R. Coulson. 1977. DNA sequencing with chain-terminating inhibitors. Proc. Natl. Acad. Sci. USA 74:5463-5467.

37. Schachter, J., J. Banks, N. Sugg, M. Sung, J. Storz, and K. F. Meyer. 1974. Serotyping of Chlamydia. I. Isolates of ovine origin. Infect. Immun. 9:92-94.

38. Smith, G. E., and M. D. Summers. 1980. The bidirectional transfer of DNA and RNA to nitrocellulose of diazobenzyloxymethyl-paper. Anal. Biochem. 109:123-129.

39. Stephens, R. S., R. Sanches-Pescador, E. A. Wagar, C. Inouye, and M. S. Urdea. 1987. Diversity of Chlamydia trachomatis major outer membrane characterization. J. Immunol. 128:1083-1089.

40. Storey, C., M. Lusher, and S. J. Richmond. 1992. Use of comparative MOMP gene sequence data for subdivision of Chlamydia psittaci species, p. 25. In P.-A. Mardh et al. (ed.), Proceedings of the European Society for Chlamydia Research. Uppsala University Centre for STD Research, Uppsala, Sweden.

41. Storz, J. 1988. Overview of animal diseases induced by chlamydial infections, p. 167-192. In A. L. Barron (ed.), The microbiology of Chlamydia. CRC Press, Boca Raton, Fla.

42. Timms, P., F. W. Eaves, A. A. Girjes, and M. F. Lavin. 1988. Comparison of Chlamydia psittaci isolates by restriction endonuclease and DNA probe analyses. Infect. Immun. 56:287-290.

43. Vogelstein, B., and D. Gillespie. 1979. Preparative and analytical purification of DNA from agarose gels. Proc. Natl. Acad. Sci. USA 76:615.

44. Watson, M. W., P. R. Lambden, and I. N. Clarke. 1991. Genetic diversity and identification of human infection by amplification of the chlamydial 60 kilodalton cysteine-rich outer membrane protein gene. J. Clin. Microbiol. 29:1188-1193.

45. Weisburg, W. G., T. P. Hatch, and C. R. Woese. 1986. Eubacterial origin of chlamydiae. J. Bacteriol. 167:570-574.

46. Weisburg, W. G., T. Hatch, and C. R. Woese. 1990 . Genbank submission no. M59178. Chlamydia trachomatis 16S ribosomal RNA gene. 